\title{
Como localizar o epicentro de um terremoto?+*
}

\section{Francisco Catelli $^{1}$}

Programa de Pós-Graduação em Ensino de Ciências e Matemática

Universidade de Caxias do Sul

José Arthur Martins ${ }^{2}$

Centro de Ciências Exatas e da Tecnologia

Universidade de Caxias do Sul

Programa de Pós Graduação em Educação Científica e Tecnológica - UFSC

Odilon Giovannini ${ }^{3}$

Programa de Pós-Graduação em Ensino de Ciências e Matemática

Universidade de Caxias do Sul

Caxias do Sul - RS

\section{Resumo}

A localização do foco de origem de terremotos envolve conceitos de física interessantes e motivadores, além de não exigir conhecimentos prévios muito elaborados. A resposta à questão "como localizar o epicentro de um terremoto?" é construída a partir de considerações sobre ondas mecânicas longitudinais (ondas " $p$ ”) e transversais (ondas "s") e da diferença no tempo de chegada a uma estação sismológica de cada uma dessas ondas. Uma simulação da técnica de medição de distância ao epicentro por meio de dois carros a pilha movendo-se com velocidades diferentes é apresentada; a necessidade de dados de mais de uma estação para a localização precisa é discutida. Ondas longitudinais e transversais numa barra metálica são exploradas num ambiente de laboratório didático, e técnicas para a medição da velocidade de uma onda longitudinal é apresentada. Conclui-se que não existe "uma” resposta a

\footnotetext{
${ }^{+}$How to locate the epicenter of an earthquake?

* Recebido: agosto de 2014.

Aceito: dezembro de 2014.

${ }^{1}$ E-mail: Fcatelli@ucs.br

2 E-mail: jamartin@ucs.br

${ }^{3}$ E-mail: ogiovanj@ucs.br
} 
perguntas como a que é apresentada aqui, e sim respostas em níveis crescentes de complexidade. A decisão sobre qual nível de resposta é satisfatório cabe ao estudante, e decorre em geral do tamanho de sua motivação para o tema.

Palavras-chave: Terremotos; Epicentro; Cinemática; Ondas mecânicas.

\begin{abstract}
The location of the focus of origin of earthquakes involves concepts of Physics, which are interesting and motivating and do not require very elaborate prior knowledge. The question "how to locate the epicenter of an earthquake?" is answered by taking into account some considerations of mechanical longitudinal waves ( $p$-waves) and transverse waves ( $s$ waves), and the time difference of arrival in a seismological station of each one of these waves. A simulation of the technique to measure distances of the epicenter is made with support of two toy cars moving at different speeds; the need for data from more than just one station to the have a more precise location is discussed. The laboratory exploration of longitudinal and transverse waves in a metal rod is also discussed, and techniques to measure the speed of longitudinal waves are presented. There is not a "single one" answer to questions such as the one presented here, but there are many answers that present increasing levels of complexity. The decision of what level of response is satisfactory is on the students, and, in general, it is a consequence of his/her motivation on the subject.
\end{abstract}

Keywords: Earthquakes; Epicenter; Kinematic; Mechanical waves.

\title{
I. Introdução
}

Felizmente, terremotos são raros no Brasil. Seus efeitos, diretos ou indiretos, podem ser devastadores: o terremoto de Anchorage, no Alasca, em 1964, liberou uma energia equivalente a cerca de 200 bilhões de toneladas de TNT (FUNBEC - ESCP, 1973, p. 19). Mais recentemente, em março de 2011, os efeitos indiretos de outro terremoto provocaram ondas no mar causando um tsunami que produziu uma enorme destruição no Japão. É difícil não ficar impressionado com a magnitude de tais eventos; seu monitoramento é fundamental para evitar tragédias com milhares de vítimas fatais. A determinação do local onde eles têm origem, bem como o horário, é de importância capital: cartas de distribuição de ocorrência de terremotos são de utilidade evidente. Então, a pergunta que dá o título a esse trabalho se situa num con- 
texto que tem o potencial de atrair a atenção dos estudantes: como determinar o local ("foco") no qual um terremoto tem origem?

As ondas mecânicas que se propagam na Terra quando ocorre um terremoto são (predominantemente) de dois tipos: transversais $(s)$ e longitudinais $(p)^{4}$. Ocorre que as ondas $p$ são mais rápidas do que as ondas $s$; um valor típico para a velocidade dessas ondas é de $v_{\mathrm{P}}=8$ $\mathrm{km} / \mathrm{s}$. As ondas transversais $(s)$ são mais lentas 5 , tipicamente $v_{\mathrm{S}}=4,5 \mathrm{~km} / \mathrm{s}$ (HALLIDAY; RESNICK; WALKER, 2008, problema 7, cap. 16, p. 173). Sismógrafos, aparelhos que detectam pequenas vibrações do solo, registram primeiro as ondas $p$, e após um determinado intervalo de tempo $\Delta t$, que depende da distância da estação sismológica ao foco do terremoto, registram a chegada das ondas $s$, essas de $\underset{6}{\operatorname{grande}}$ potencial destruidor. De posse de $v_{\mathrm{P}}, v_{\mathrm{S}}$ e $\Delta t$, pode-se determinar a distância ao epicentro ${ }^{6}$ do terremoto.

A resposta acima é, sem dúvida, correta, mas frustrante do ponto de vista de um estudante que tenha feito a pergunta que dá título a esse trabalho. Essa frustração advém em grande parte do fato de que os elementos da resposta são, em alguma medida, obscuros para quem se aproxima pela primeira vez desse assunto, os terremotos. Então, o restante do trabalho voltar-se-á ao aclaramento desses elementos, na sequência descrita a seguir. Inicialmente será feita uma breve revisão do que são ondas mecânicas transversais e longitudinais; a seguir, o cálculo da distância ao epicentro (veja a nota de rodapé 6) será esclarecido, através de uma simulação bastante simples. Dado que a distância obtida acima é um dado unidimensional, e o epicentro precisa ser localizado em três dimensões, a forma de chegar a essa localização é brevemente descrita para o caso bidimensional; a extensão à terceira dimensão, conceitualmente simples, é mencionada. Por fim, a velocidade de ondas transversais e longitudinais em uma barra metálica é explorada em um ambiente de laboratório didático, como forma de "materializar" alguns dos conceitos abordados acima.

\footnotetext{
4 A abreviatura " $p$ " vem do inglês "pressure" ou pressão. As ondas $p$ são um exemplo do que se denomina em física de "ondas longitudinais". Já a abreviatura "s" vem do inglês "shear", ou cisalhamento, que é o que ocorre, por exemplo, quando um papel é cortado com uma tesoura. As ondas s são um exemplo do que se denomina em física de "ondas transversais".

${ }^{5}$ Uma curiosidade, que não será explorada nesse trabalho: as ondas $s$, transversais, se propagam em meio sólido, mas não o fazem em meios líquidos, como é o caso do núcleo externo (líquido) da Terra; já as ondas $p$ se propagam tanto nos sólidos como nos líquidos. As reflexões e refrações dessas ondas podem fornecer informações preciosas acerca do interior da Terra (HEWITT, 2002, p. 335). De fato, esses fenômenos são utilizados em um dos métodos de prospecção de petróleo, conhecido como "sísmica de reflexão".

${ }^{6} \mathrm{O}$ epicentro é a projeção na superfície da Terra do local (foco) onde ocorre o terremoto, desconsiderada, portanto, a profundidade. O foco, no interior da Terra, onde tem origem o evento, é denominado hipocentro (FUNBEC - ESCP, 1973, v. 1, p. 19). Se a distância da estação sismológica onde é feita a detecção é grande, relativamente à profundidade do foco do terremoto, então a distância da estação ao epicentro e a distância da estação ao hipocentro podem ser tomadas como aproximadamente iguais.
} 


\section{Ondas mecânicas transversais e longitudinais - uma revisão breve}

Se uma pedra é jogada no meio de um lago, ela perturbará a superfície da água, e essa perturbação se propagará como um círculo que aumenta gradualmente de diâmetro, até ocupar o lago todo. Uma boia de anzol, na borda do lago, subirá e descerá no momento que a perturbação a atingir. Alguns fatos, bem conhecidos, podem ser evocados aqui. Não é a água que estava no meio do lago que "viajou" até a boia, perturbando-a. Não houve "transporte" de matéria (água), e sim, de energia; uma parte dessa energia foi responsável pela oscilação da boia. Outro fato curioso pode ser destacado: a perturbação na água provocada pela pedra ao cair é vertical, ao passo que a propagação de parcela dessa energia se dá horizontalmente, ao longo da superfície do lago. Trata-se aqui de um "pulso" transversal, ou seja, a perturbação que o provoca é perpendicular à direção de propagação. Uma onda transversal pode ser imaginada supondo que pedras são lançadas periodicamente no mesmo ponto; o conjunto de "círculos" em movimento que se instalam sobre a superfície do lago é denominado então de "onda transversal". A Fig. 1 é uma representação de uma dessas ondas, produzida numa corda tensionada.

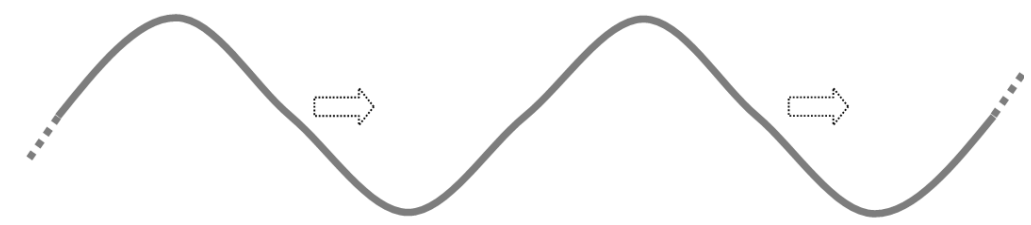

Fig. 1 - Ondas transversais numa corda flexível. Um pequeno elemento da corda se move para cima e para baixo, enquanto que a perturbação se propaga horizontalmente (para a esquerda, na figura), o que caracteriza uma onda transversal.

Imagine agora um elemento de volume do solo (no qual ondas sísmicas do tipo $s$ podem se propagar) em forma de cilindro (à esquerda na Fig. 2); ao ser submetido a uma tensão cisalhante, o cilindro se deforma (Fig. 2, à direita). Essa tensão cisalhante provoca uma deformação $\Delta x$ no cilindro, e pode ser intuída imaginando uma pilha de cartas de um baralho, onde a primeira e a última cartas são submetidas a forças, como as representadas na figura .
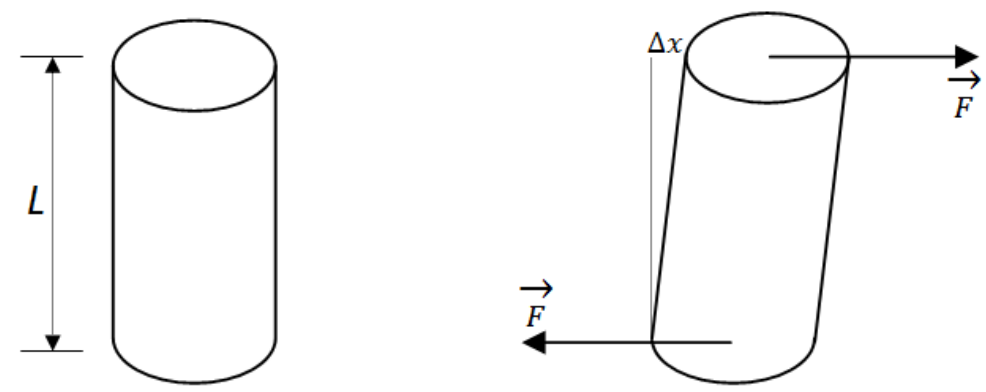

Fig. 2 - Tensões cisalhantes num volume elementar do solo, em forma de cilindro.

7 Ver, por exemplo, http://www.iag.usp.br/ agg_1400200/moddata/GEOFISICA/apostila1-sismo_p1.pdf 
As ondas longitudinais obedecem às mesmas premissas (não há transporte de matéria, há transporte de energia), com uma diferença. A perturbação que produz um pulso longitudinal tem a mesma direção da propagação desse pulso, daí a denominação "longitudinal". Na Fig. 3, alguns anéis de uma mola longa são aproximados uns dos outros, ao longo da linha do eixo da mola. Se esses anéis forem subitamente liberados, esse padrão de anéis próximos uns dos outros viajará pela mola, na mesma direção de seu eixo. Essa é a descrição de um pulso longitudinal; se eles forem produzidos periodicamente, uma onda longitudinal se propagará pela mola (HEWITT, 2002, p. 335).

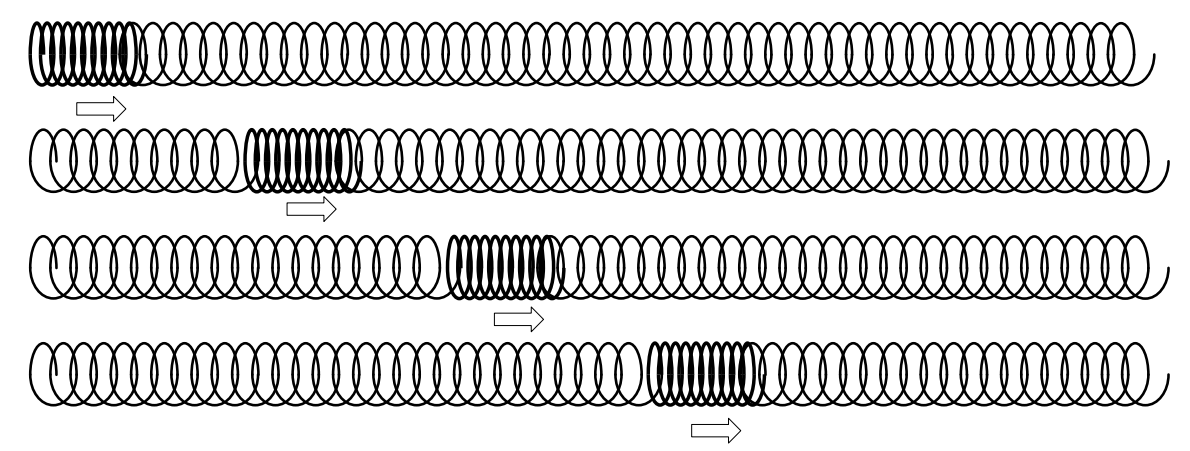

Fig. 3 - Alguns dos anéis do início da mola superior da figura são aproximados uns dos outros, e em seguida liberados. Essa "compressão" dos anéis se propaga ao longo da mola, caracterizando assim um pulso longitudinal. Compressões como essa, produzidas periodicamente, dão origem a uma onda longitudinal que se propagará ao longo da mola.

O que foi dito acima se refere a ondas cujo meio de propagação é material (a água, um elástico tensionado, uma mola, o ar). Já as ondas eletromagnéticas (um exemplo delas é a luz) propagam-se mesmo em volumes vazios do espaço (vácuo); trata-se de ondas transversais. As ondas eletromagnéticas não são objeto de estudo nesse trabalho.

\section{A qual distância o carro rápido ultrapassou o lento?}

Imagine a seguinte situação: ao viajar por uma autoestrada, você para, com a intenção de pedir informações aos guardas de uma patrulha rodoviária. Enquanto você conversa com um dos patrulheiros, um automóvel passa, à velocidade limite da rodovia, $80 \mathrm{~km} / \mathrm{h}$. Essa velocidade é aferida pelo radar (fixo) de um segundo patrulheiro. Decorridos três minutos, um segundo automóvel, esse mais lento, também tem sua velocidade aferida pelo mesmo radar: $60 \mathrm{~km} / \mathrm{h}$. Fica então a pergunta: a qual distância $x$ em relação ao local onde se encontra a patrulha o automóvel rápido ultrapassou o lento, supondo que as velocidades de ambos se mantiveram constantes? Esse problema é análogo ao de determinar a distância ao epicentro de um terremoto: $v_{\mathrm{P}}$ seria análoga à velocidade do carro rápido, $v_{\mathrm{S}}$, à do carro lento, e $\Delta t$ corresponderia aos três minutos referidos acima. A solução do problema dos carros é simples: dado que as duas velocidades são uniformes, pode-se escrever o que segue. 


$$
v_{p}=\frac{x}{t_{1}} ; v_{s}=\frac{x}{t_{2}}
$$

A distância $x$ vai do ponto onde o carro lento, com velocidade $v_{s}$, foi ultrapassado pelo carro rápido, de velocidade $v_{p}$, até a patrulha rodoviária; $t_{1}$ é o tempo gasto pelo carro lento para percorrer essa distância. O tempo $t_{2}$ é definido da mesma forma, dessa vez do ponto de vista do carro rápido, de velocidade $v_{\mathrm{s}}$. Nem $t_{1}$ nem $t_{2}$ são conhecidos, mas podemos escrevê-los em termos de sua diferença, essa sim conhecida (3 minutos):

$$
\Delta t=t_{2}-t_{1}=\frac{x}{v_{s}}-\frac{x}{v_{p}}
$$

Rearranjando e explicitando em $x$ :

$$
x=\Delta t \frac{v_{s} v_{p}}{v_{p}-v_{s}} .
$$

Temos, então, a resposta ao problema dos carros: a equação (3) nos diz que, para $v_{s}=60 \mathrm{~km} / \mathrm{h}, v_{p}=80 \mathrm{~km} / \mathrm{h}$ e $\Delta t=(3 / 60) \mathrm{h}$, ou $3 \mathrm{~min}$, a ultrapassagem ocorreu a $12 \mathrm{~km}$ mais para trás.

\section{Simulando a ultrapassagem num laboratório didático}

Uma versão "de laboratório" do problema dos carros pode ser executada, desde que carros a pilha com velocidades diferentes estejam disponíveis. Praticamente qualquer carro a pilha (de brinquedo) deve servir. Veja a Fig. 4-a e sua legenda.

A atividade descrita a seguir tem sido realizada em oficinas de ondas mecânicas periodicamente oferecidas aos alunos do ensino médio que participam do projeto PETROFUT (VILLAS-BOAS; MARTINS; GIOVANNINI, 2012). Para obter velocidades diferentes, um dos carros utilizados ${ }^{8}$ foi "mexido": as duas pilhas "C" de 1,5 V que energizam o motor, originalmente conectadas em série, foram conectadas em paralelo. Com isso, a velocidade desse carro diminuiu consideravelmente. O procedimento, no ambiente de sala de aula, é o seguinte: primeiro, as velocidades dos dois carros são determinadas de forma direta, medindo o tempo que cada um deles leva para percorrer a distância de $1 \mathrm{~m}$. As velocidades obtidas com esses dados são registradas em cada carro, por meio de uma etiqueta autocolante (Fig. 4-b). Em um segundo momento, é efetuada a "corrida": os dois carros são ligados, e colocados no solo ao mesmo tempo; um "cronometrista" na linha de chegada, a uma distância $x$ de $\approx 10 \mathrm{~m}$ (não conhecida, em princípio, pelos alunos), dispara seu cronômetro quando o carro rápido (com velocidade $v_{p}$ ) passa por ele, e trava o cronômetro quando o carro lento (com velocidade $v_{s}$ ) passar pelo mesmo ponto. Nessas condições, o problema do epicentro do terremoto é simulado de forma plausível, dado que a distância $x$ não é (ainda) conhecida, mas $\Delta t, v_{s}$ e $v_{p}$ o são. A

\footnotetext{
${ }^{8}$ Os carros utilizados foram produzidos especificamente para uso em laboratório (PASCO ME 9780). Mas, como mencionado no texto, qualquer carro a pilhas de brinquedo deve servir, desde que sejam feitas modificações na alimentação, como as sugeridas (pilhas em paralelo, em vez de em série, por exemplo).
} 
simulação termina com a comparação entre a distância $x$ obtida pela equação (3) e a obtida por medição direta.

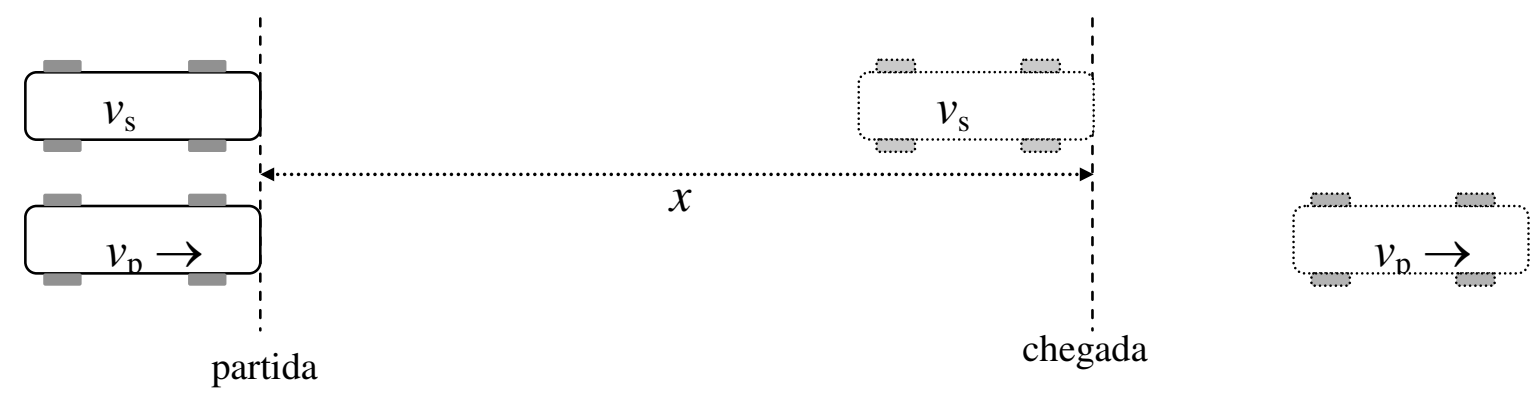

Fig. 4-a-O carro com velocidade $v_{s}$, mais lento, sai da linha de partida ao mesmo tempo que o carro de velocidade $v_{p}$, mais rápido. Quando o carro $v_{p}$ cruza a linha de chegada, um cronômetro é disparado, e é travado depois, quando o carro vs cruza por sua vez a linha de chegada, registrando assim o intervalo de tempo $\Delta t$ que separa a passagem dos dois carros pela linha de chegada. De posse de $v_{s}, v_{p}$ e $\Delta t$, a distância x pode ser prevista, a partir da equação (3). Finalmente, o resultado da previsão é comparado com a medição direta de $x$.

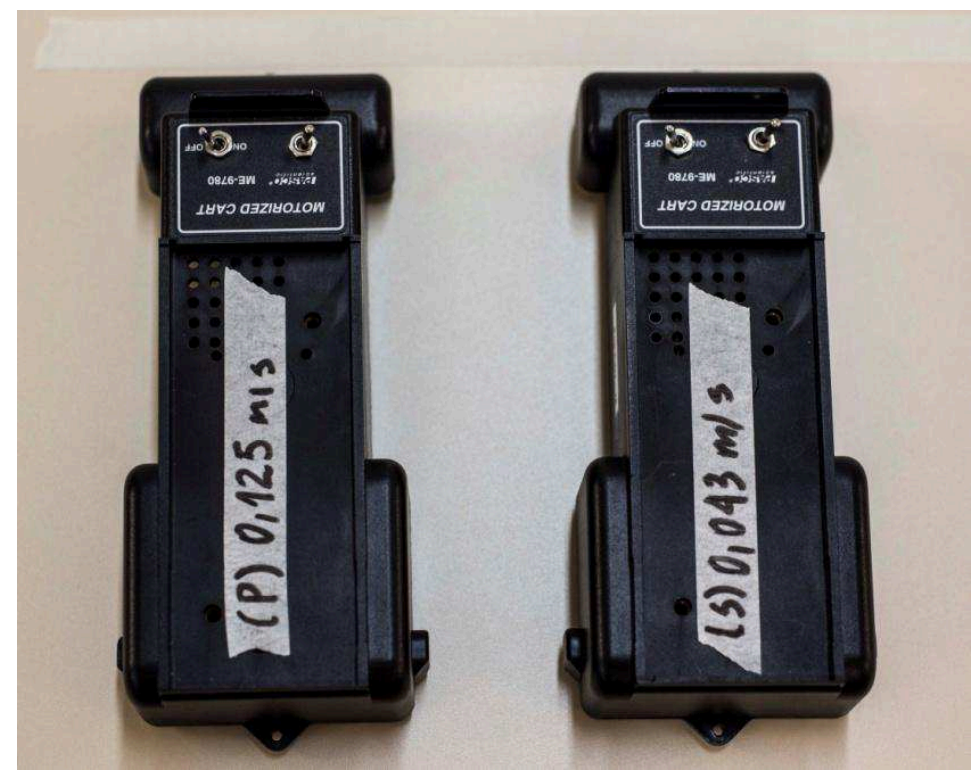

Fig. 4-b - Os carros a pilha empregados na simulação do movimento de ondas s e ondas p, descrita acima. Os valores das velocidades aparecem nas etiquetas coladas nos carros.

\section{Uma estação sismológica só não basta!}

Vejamos agora um cálculo, com velocidades "autênticas" de ondas $s$ e ondas $p$, que se propagam a partir do foco de um terremoto: para $v_{\mathrm{s}}=4,5 \mathrm{~km} / \mathrm{s}, v_{\mathrm{p}}=8,0 \mathrm{~km} / \mathrm{s}$ e $\Delta \mathrm{t}=180 \mathrm{~s}$ 
(medido num sismógrafo), a distância $x$ ao epicentro poderia ser estimada através da expressão (3) em aproximadamente $1851 \mathrm{~km}$, supondo que as ondas $s$ e $p$ se propagaram em linha reta (HALLIDAY; RESNICK; WALKER, op. cit.). Mas há um problema, que não aparece nessa simulação de carros rápidos e lentos em uma estrada, nem no cálculo (com dados reais) apresentado acima. No caso dos carros, a distância x é medida sempre ao longo da estrada, em uma dimensão, mas no caso de um terremoto, as ondas $s$ e $p$ se propagam em todas as direções, a partir do foco do terremoto. Para começar, podemos simplificar um pouco a situação supondo um sismo próximo à superfície da Terra, e distâncias não excessivamente grandes quando comparadas com o raio desta (em outras palavras, tudo ocorre aproximadamente num plano). Conhecer $x$ significa então saber que o epicentro do terremoto está sobre algum dos pontos de um círculo de raio $x$. Mas em qual ponto do arco desse círculo está o epicentro? Então, os dados de uma única estação sismológica não bastam para determinar a localização completa do foco do terremoto, seriam necessários os dados de outras estações. A figura 5 ilustra essa situação, para duas estações; a distância $x_{1}$ pode ser vista agora como o raio de um círculo cujo centro está posicionado na estação $1\left(\mathrm{E}_{1}\right)$, e o mesmo vale para a distância $x_{2}$ e a estação $2\left(\mathrm{E}_{2}\right)$. Somente dois pontos, os pontos de intersecção dos dois círculos, são igualmente consistentes com as distâncias medidas nas duas estações. Em outras palavras, o foco do terremoto estaria próximo de uma dessas intersecções. É fácil perceber que, com os dados de uma terceira estação ${ }^{9}$, o foco poderia ser determinado de forma unívoca (FUNBEC - ESCP, 1973, p. 19). Os dados de três (ou mais) estações permitiriam então determinar univocamente o ponto onde ocorreu o sismo. Mas, se forem consideradas (no interior da Terra) cascas esféricas em vez de círculos, os dados de três estações permitiriam uma solução tridimensional, onde a latitude, a longitude e a profundidade do foco do terremoto (e também o horário que ele ocorreu, mas não tratamos desse aspecto aqui) poderão ser determinadas.

\section{Ondas mecânicas em meios sólidos no laboratório didático}

Nesse ponto, a pergunta do título (como localizar o epicentro de um terremoto?) pode ser considerada respondida de forma um pouco mais completa, consistente e acessível ao público que por ela se interessa. Mas ainda é possível colher pelo menos um dividendo adicional. Explorar diretamente ondas mecânicas produzidas no interior da crosta terrestre não é, em princípio, uma tarefa experimental fácil e imediatamente acessível. Mas há um "objeto", que pode ser improvisado no ambiente escolar, no qual tanto as ondas transversais quanto as longitudinais podem ser visualizadas (mais exatamente, ouvidas) e mesmo, dependendo do interesse, medidas. Esse objeto é uma simples barra de metal (ferro, alumínio, latão, ou o que estiver disponível, WONG, 1997). Inicialmente, será necessário, além da barra de metal, de $100 \mathrm{~cm}$ de comprimento e $1 \mathrm{~cm}$ de diâmetro, um martelo. Essas dimensões são apenas indicativas: qualquer outro comprimento e (ou) diâmetro comparáveis servirão igualmente bem.

\footnotetext{
${ }^{9}$ As três estações podem estar posicionadas aleatoriamente, exceto sobre uma mesma linha.
} 


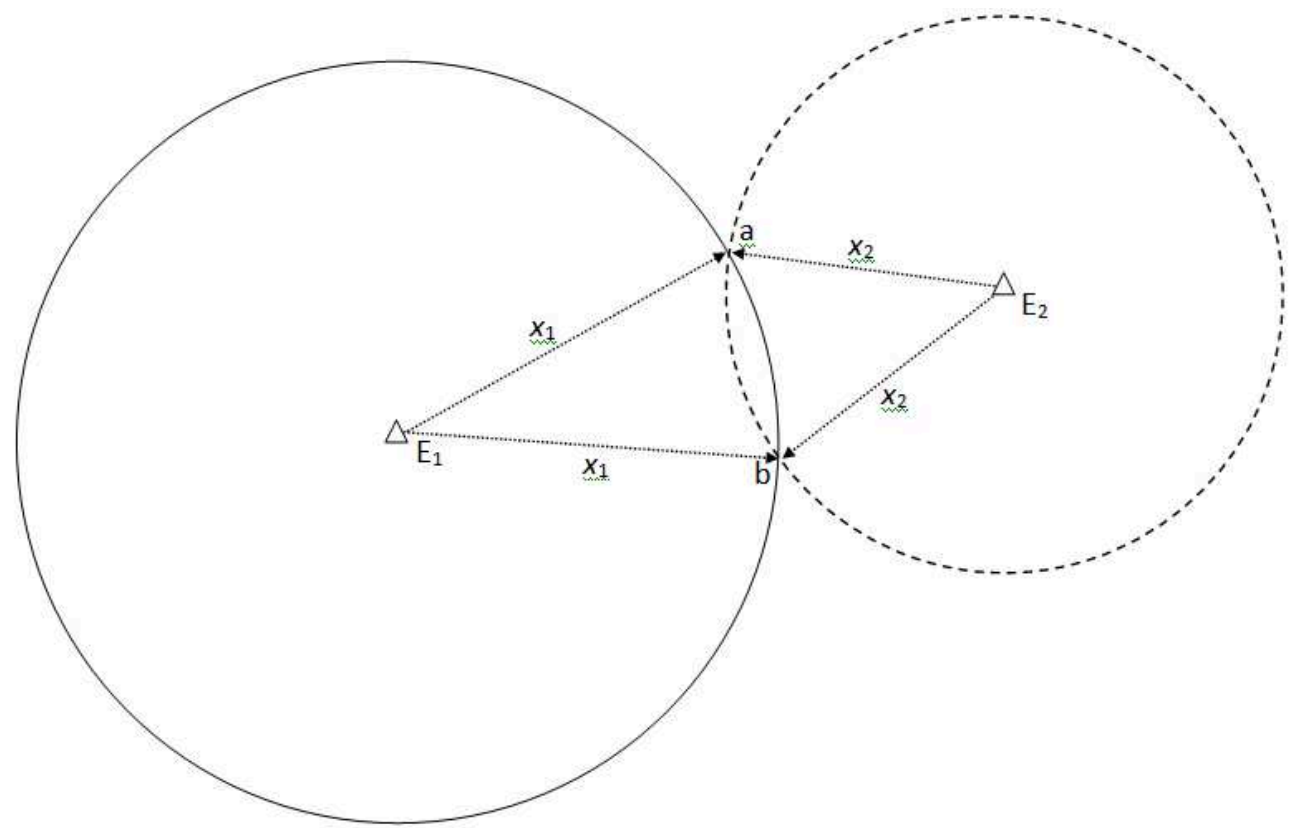

Fig. 5 -Duas estações sismológicas, $E_{1}$ e $E_{2}$, e as distâncias $x_{1}$ e $x_{2}$ ao foco do terremoto (ver texto). Apenas os pontos a e b são igualmente consistentes com as distâncias medidas nas duas estações; o foco do terremoto estará próximo a um deles.

Em meios sólidos as ondas podem ser predominantemente transversais e longitudinais. Iniciemos com as ondas longitudinais. Suspenda a barra por meio de barbantes, como na Fig. 6, e bata com o martelo numa de suas extremidades. Você ouvirá um som bastante agudo e surpreendentemente sustentado (você pode ouvi-lo por uns 10 segundos, ou mais). Trata-se de uma evidência acústica das ondas $p$; quando a extremidade é golpeada, ela é (microscopicamente) deformada, essa deformação viaja com uma grande velocidade ao longo da barra, o que caracteriza uma onda longitudinal (veja também a Fig. 3). Ao chegar à extremidade oposta, essa deformação é "refletida" de volta, e assim sucessivamente, por algumas dezenas de milhares de vezes. Essas idas e voltas sucessivas e igualmente espaçadas no tempo produzem uma onda, cuja frequência, audível, se situa por volta de $2,5 \mathrm{kHz}$, para uma barra de alumínio de $1 \mathrm{~m}$ de comprimento.

Tal como ocorre com as ondas $p$ e as ondas $s$ dos terremotos, a velocidade dessas ondas numa barra metálica é sensivelmente diferente. A velocidade da onda longitudinal na barra pode ser determinada a partir de um aplicativo de smartphone (ver Fig. 7): há aplicativos afinadores de instrumentos musicais que fornecem, além do tom, a frequência da onda detectada. Um excelente tratamento teórico da propagação de ondas longitudinais em um modelo feito com carros unidos por molas é feito em Black e Ogborn, 1976, p. 55 e seguintes. Na sequência, esses autores sugerem uma técnica para a medição da velocidade de ondas transversais numa barra através de um gerador de sinais e um osciloscópio. Sawicki (2003) apresenta outra técnica, na qual um imã circular e uma bobina enrolada numa extremidade da haste são usados como recurso de detecção. Sensores piezo elétricos de cerâmica ou células de 
carga (strain gauges), colados a uma das extremidades da barra, e conectados a osciloscópios também podem ser empregados, com excelentes resultados.

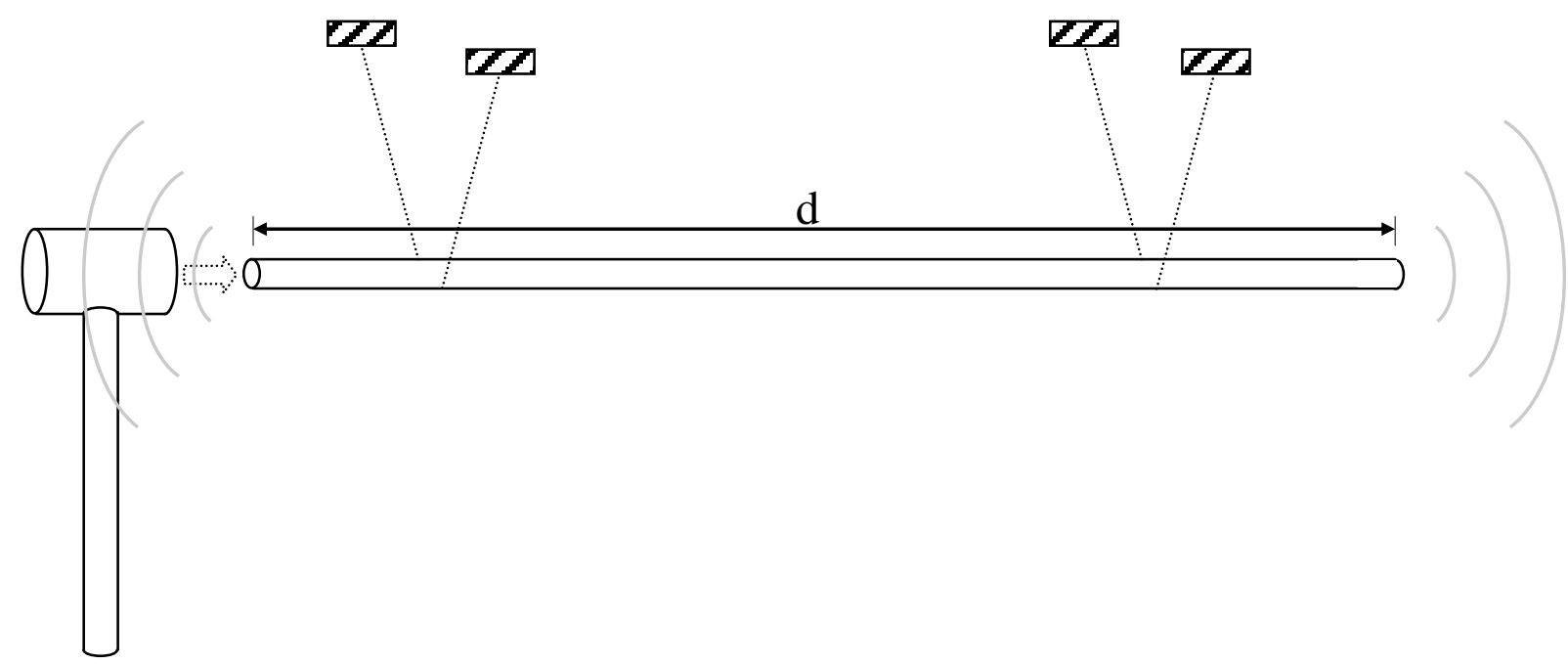

Fig. 6 - Ondas longitudinais produzidas numa barra, golpeando-a em uma das extremidades por meio de um martelo.

De posse desta frequência, o cálculo pode ser compreendido de modo bastante intuitivo: entre dois retornos sucessivos da onda de compressão à extremidade da barra próxima ao ouvido, a distância total percorrida terá sido $2 d$ (correspondente à ida e à volta), num intervalo de tempo que pode ser associado ao período $T$ de oscilação do tom audível ou, de forma equivalente, ao inverso da frequência da onda longitudinal $f_{\mathrm{p}}$. Assim,

$$
v_{p}=\frac{2 d}{T}=2 d f_{p} .
$$

Na medição de uma onda longitudinal em uma barra de alumínio de $(100 \pm 0,3) \mathrm{cm}$ de comprimento, a frequência medida (Fig. 7) foi de (2489 \pm 5$) \mathrm{Hz}$, o que levou a uma velocidade $v_{p}$ de $(4978 \pm 25) \mathrm{m} / \mathrm{s}$ (ou impressionantes $17900 \mathrm{~km} / \mathrm{h}$ !). A velocidade encontrada é consistente com os valores apresentados na literatura, de $5000 \mathrm{~m} / \mathrm{s}$ para o alumínio (Lide, 2004. p. 2396, sec. 14-41) $)^{10}$.

A medição da frequência fundamental das ondas transversais que se instalam na barra quando, suspensa como na Fig. 4, ela é percutida em seu centro numa direção perpendicular torna-se instrumentalmente mais complexa, devido em especial ao grande número de harmônicos produzido. A medição com o aplicativo sugerido acima torna-se inconclusiva e, nes-

\footnotetext{
10 As ondas longitudinais em uma barra cilíndrica, na qual o diâmetro é muito menor que o comprimento de onda considerado, são denominadas por Lide (op. cit.) de ondas extensionais ("extensional waves").
} 
sas condições, torna-se imperativo o uso de um analisador de espectro ${ }^{11}$. De qualquer modo, é fácil perceber, de ouvido, que o tom das ondas longitudinais é mais alto (mais agudo), enquanto que o tom percebido ao produzir ondas transversais é nitidamente mais grave. $\mathrm{O}$ valor apresentado na literatura para a velocidade $\left(v_{s}\right)$ das ondas transversais no alumínio (Lide, op. cit.) é de $3040 \mathrm{~m} / \mathrm{s}$, a qual, como esperado, é menor que a velocidade $v_{p}$ (longitudinal) nesse mesmo meio, o alumínio. Para lembrar, as ondas no interior da Terra, produzidas após um terremoto, também guardam essa mesma propriedade: as ondas $p$ são mais velozes que as ondas $s$.

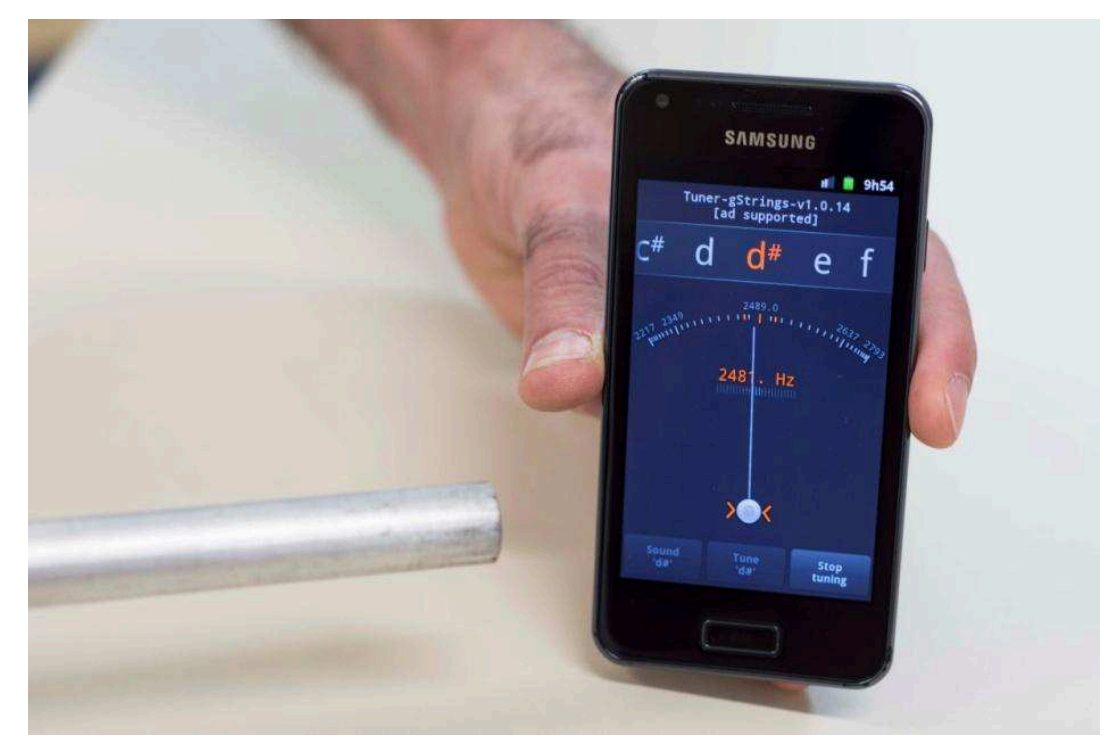

Fig. 7 - Frequência de uma onda longitudinal numa barra de alumínio (1 $\mathrm{m}$ de comprimento por $2 \mathrm{~cm}$ de diâmetro), detectada por um aplicativo de smartphone: um afinador de instrumentos musicais ${ }^{12}$. Note que o aplicativo fornece, além do tom, o valor numérico da frequência: $2489 \mathrm{~Hz}$.

\section{Conclusões}

A técnica apresentada para a "determinação" do ponto em que o carrinho rápido ultrapassa o lento permite uma materialização de um conceito essencial no âmbito da sismologia, que é a determinação do epicentro de um terremoto em função do intervalo de tempo entra a chegada das ondas $p$ e das ondas $s$ a um sismógrafo. Essa materialização (potencial) pode inclusive tornar a aprendizagem da cinemática mais significativa; os estudantes encontram aí uma aplicação inesperada de fórmulas simples, por eles estudadas em outro contexto.

\footnotetext{
11 Para frequências de áudio, podem ser baixados sem custo no computador osciloscópios virtuais, tais como o Visual Analyser®, os quais permitem identificar grande parte das frequências (harmônicos) presentes numa barra, quando percutida nas formas indicadas no texto.

12 Trata-se do "GStrings", da plataforma Android. O aplicativo pode ser baixado gratuitamente.
} 
Outro contexto explorado nesse trabalho diz respeito ao uso de fórmulas da cinemática em fenômenos acústicos, os quais, por sua vez, são associados a fenômenos sismológicos. Esse "trânsito" por diversas áreas, desde que proposto com cuidado pelo professor, pode estimular os alunos a enxergarem elementos comuns, a identificarem um mesmo recurso (fórmulas de cinemática) desempenhando papeis diversos em contextos diferentes. Esse é, sem dúvida, um dividendo didático de grande importância: dito de maneira um tanto informal, trata-se de "fazer o máximo de física com o mínimo de fórmulas".

Um dividendo didático adicional é o que diz respeito aos diversos níveis que uma resposta pode assumir. Não basta que a resposta a uma questão seja "correta", pelo menos não num contexto de ensino e aprendizagem. Uma resposta, apesar de correta, pode, naquele momento, não fazer sentido a quem dela tenta se apropriar. Podemos "entender" algo, às vezes, quase que imediatamente, mas se o alvo é "aprender", precisamos ter paciência. Aprender leva mais tempo, e essa é uma das razões pelas quais "entender" não é o mesmo que "aprender”, lembra-nos Gaspar (2014, p. 190-191). É possivelmente o que ocorre com alguém, não familiarizado com o tema, que leia apenas o item 1 desse trabalho: não existem (ainda) conexões, analogias, ilustrações em número suficiente que permitam uma apreensão que vá além de uma simples memorização de algum detalhe desconexo. No restante do trabalho, parte-se em busca dessas conexões e analogias, através de elementos que sejam previamente familiares ao leitor, como o recurso aos carros de pilha; a teorização que é feita a partir deles, com base na cinemática elementar, é o passo seguinte na direção do "aprender".

Os elementos destacados acima (e eventualmente outros não mencionados nesse trabalho) possuem um objetivo comum: uma aprendizagem a mais significativa possível. E "significação" não é algo que o estudante ou tem ou não tem. Há gradações. A interpretação de um fenômeno físico (nesse caso, o terremoto) vai gradualmente ser tornando mais sofisticada e completa na medida em que o fenômeno é retomado ou reencontrado. Por vezes, essa (re) interpretação se torna também mais complexa, o que desafia e provoca. Em alguns casos muito especiais, esse desafio - aliado a outras condições favoráveis - é tão intenso, que acaba por definir o futuro profissional do estudante envolvido: é um engenheiro de minas, um físico, um geógrafo que começa a se constituir.

\section{Agradecimento}

Os autores agradecem à FINEP e também aos revisores do CBEF, pelas valiosas sugestões oferecidas.

\section{Bibliografia}

BLACK, P. J.; OGBORN, J. Física - Ondas y Oscilaciones. Coleção Ciências Avançadas Nuffield. Barcelona: Editorial Reverté, 1976. V. 4. 
FUNBEC - ESCP Earth Science Curriculum Project. Investigando a Terra. São Paulo: Mc Graw Hill, 1973.

GASPAR, A. Atividades Experimentais no Ensino de Física. Uma Nova visão Baseada na Teoria de Vigotski. São Paulo: Editora Livraria da Física, 2014.

HALLIDAY, D.; RESNICK, R.; WALKER, J. Fundamentos de Física: Gravitação, Ondas e Termodinâmica. 8. ed. São Paulo: LTC, 2008. v. 2.

HEWITT, P. Física Conceitual. 9. ed. Porto Alegre: Bookman, 2002.

LIDE, D. R. CRC Handbook of Chemistry and Physics. Boca Raton (Flórida): CRC Press, 2005.

SAWICKY, C. Induced Current Measurement of Rod Vibrations. The Physics Teacher, v. 41, jan. 2003.

VILLAS-BOAS, V.; MARTINS, J. A.; GIOVANNINI, O. PETROFUT: Novos desafios para o engenheiro do futuro. Revista Dynamis, v. 12, n. 2, p. 45, 2012.

WONG, D. D. Vibrating Rods And More. The Physics Teacher, v. 35, out. 1997. 